\title{
Exchange protein activated by cAMP enhances long-term memory formation independent of protein kinase $\mathrm{A}$
}

\author{
Nan Ma, Ted Abel, and Pepe J. Hernandez ${ }^{1}$ \\ University of Pennsylvania, Department of Biology, Philadelphia, Pennsylvania 19104, USA
}

\begin{abstract}
It is well established that CAMP signaling within neurons plays a major role in the formation of long-term memories-signaling thought to proceed through protein kinase A (PKA). However, here we show that exchange protein activated by cAMP (Epac) is able to enhance the formation of long-term memory in the hippocampus and appears to do so independent of PKA, thus demonstrating the importance of Epac-mediated signaling in memory consolidation.
\end{abstract}

The molecular mechanisms underlying long-term memory consolidation mediated by cyclic adenosine monophosphate (cAMP) signaling have been extensively studied. It is thought that cAMP regulates memory formation mainly by activating the cAMPsensitive PKA. Once activated, PKA can then phosphorylate various downstream kinases and transcription factors required for memory formation (Abel and Nguyen 2008). However, with the discovery of another major target of cAMP known as Epac (de Rooij et al. 1998; Kawasaki et al. 1998), there may be reason to reconsider the precise nature of cAMP in memory formation. Although Epac-mediated signaling has been previously studied in various in vitro preparations, hippocampal long-term potentiation studies (Gelinas et al. 2008; Holz et al. 2008), and now in memory retrieval paradigms (Ouyang et al. 2008; Kelly et al. 2009), its role in long-term memory formation or consolidation has yet to be addressed. In the present study, we examine the effects of Epac activation within the hippocampus on memory consolidation for contextual fear.

The following experiments were conducted with singly housed 2-4-mo-old male C57BL/6J mice (Jackson Laboratories). Animals were provided with water and rodent chow ad libitum and maintained on a 12-h light/dark cycle. To study the role of Epac in the hippocampus, pharmacological manipulations were conducted through targeted microinfusions into the dorsal hippocampus. First, mice were anesthetized with isoflurane, placed in a stereotaxic frame (Kopf Instruments), and implanted with a 22gauge guide cannulae (Plastics One) (stereotaxic coordinates: 1.7 $\mathrm{mm}$ posterior to bregma, $\pm 1.5 \mathrm{~mm}$ from midline, and $-1.5 \mathrm{~mm}$ from the skull surface). Animals were allowed to recover for $1 \mathrm{wk}$, then handled for 1-2 min on three consecutive days before contextual fear conditioning. Contextual fear memory was examined by placing mice in a standard conditioning chamber (Med Associates) for $2 \mathrm{~min}, 28 \mathrm{sec}$ after which a single 2 -sec footshock was given. Mice were left in the chamber for an additional $30 \mathrm{sec}$ before being returned to their home cage. Long-term memory was assessed by measuring freezing behavior (defined as complete immobility, except for breathing) during a 5-min test session in the same chamber $24 \mathrm{~h}$ after training. Drugs were injected bilaterally $(0.25 \mu \mathrm{L} / \mathrm{min}$ for $2 \mathrm{~min})$ through injection cannulae that were connected to Hamilton microsyringes via polyethylene tubes

'Corresponding author.

E-mail pepej@sas.upenn.edu; fax (215) 573-1297.

Article is online at http://www.learnmem.org/cgi/doi/10.1101//m.1231009. using a microinfusion pump (Harvard Apparatus). One minute was allowed for diffusion before the injection cannulae were removed. All experiments were conducted in accordance with the policies of the Institutional Animal Care and Use Committee of the University of Pennsylvania and the National Institutes of Health.

To begin our examination of Epac in memory formation, we tested whether a single intrahippocampal infusion of the PDEresistant cAMP analog Sp-cAMPS (Yusta et al. 1988) would enhance the consolidation of contextual fear memory. Although Sp-cAMPS is commonly used as an activator of protein kinase A (PKA), it is also capable of activating Epac (Christensen et al. 2003). In this experiment, mice were fear conditioned with a single low-intensity footshock $(0.75 \mathrm{~mA})$ to better detect drug-related increases in freezing. This procedure is often used to avoid ceiling effects in freezing levels that might be observed if higher footshock intensities are used (Tronson et al. 2006). Immediately after training, mice received 0, 4.5, or $9 \mu$ g of Sp-cAMPS (Sigma-Aldrich) bilaterally into the dorsal hippocampus. Long-term memory was assessed $24 \mathrm{~h}$ later by measuring freezing behavior in the training context. Mice that received $4.5 \mu \mathrm{g}$ of Sp-cAMPS showed significantly enhanced long-term memory relative to both the vehicle and high-dose groups $\left(F_{(2,25)}=4.11, P=0.03\right.$, ANOVA) resulting in an inverted U-shaped dose-response curve (Fig. 1A). Hormetic or biphasic responses of this type are characteristic of a broad range of physiological and behavioral responses and may represent an overcompensation in response to disruptions in homeostasis (Calabrese and Baldwin 2001). Post-hoc analysis revealed that the low-dose groups froze significantly more than either the vehicle or high-dose groups (Ps $<0.05$, Student-Newman-Keuls). These data and others (Souza et al. 2002) implicate, but cannot distinguish between Epac and PKA signaling in memory consolidation. Indeed, since Epac and PKA recruit, at least to some extent, different downstream effectors (Holz et al. 2008), such a distinction is critical to further understand the nature of memory consolidation.

To address this issue, we repeated the above experiment using the Epac-specific agonist 8-(4-chlorophenylthio)-2'-O-methyladenosine-3', 5'-cyclic monophosphate (8-pCPT-2'-O-Me-cAMP) (Enserink et al. 2002). In designing this cAMP analog, specific chemical group substitutions were made at positions critical for high-affinity binding of cAMP to PKA, thereby generating a potent and highly selective agonist for Epac (Enserink et al. 2002; Christensen et al. 2003; Bos 2006; Ster et al. 2007). Mice were 
A

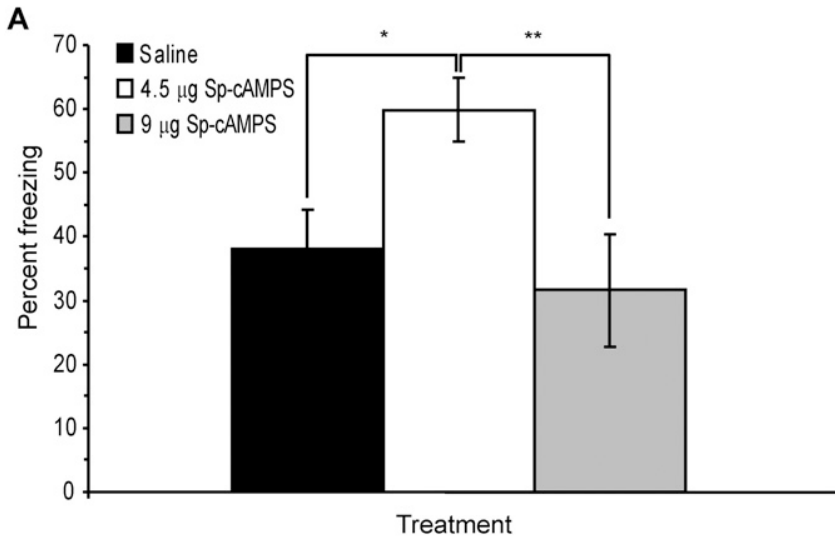

B

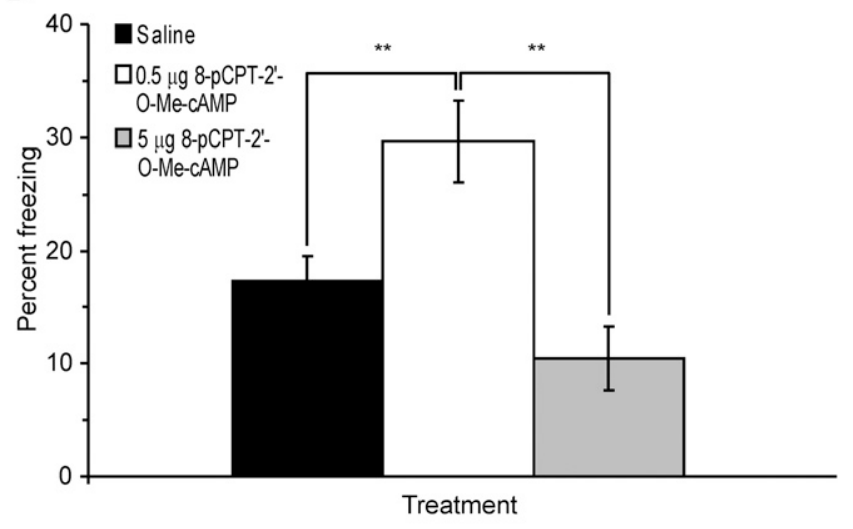

C

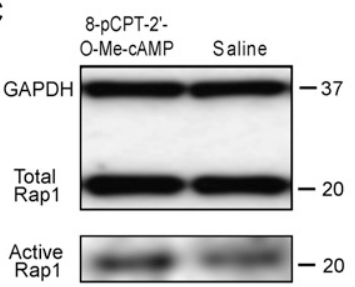

D

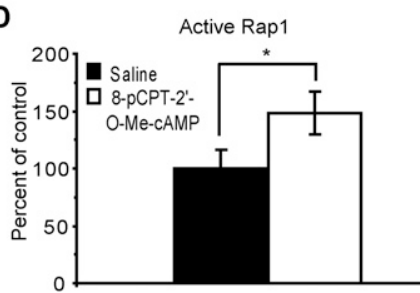

Figure 1. Epac activation in the hippocampus enhances long-term contextual fear memory. Effect of a single post-training intrahippocampal infusion of either $(A)$ the PKA/Epac activator Sp-cAMPS $(0 \mu \mathrm{g}, n=10$; $4.5 \mu \mathrm{g}, n=8 ; 9 \mu \mathrm{g}, n=10)(B)$ or the Epac-specific activator 8-pCPT-2' $-O$ Me-cAMP $(0 \mu \mathrm{g}, n=10 ; 0.5 \mu \mathrm{g}, n=10 ; 5 \mu \mathrm{g}, n=9)$. In both cases, inverted U-shaped dose response curves were obtained where the low doses significantly enhanced memory measured $24 \mathrm{~h}$ after fear conditioning. (C) A representative immunoblot of active Rap1 in the hippocampus $5 \mathrm{~min}$ after infusion of $0.5 \mu \mathrm{g}$ 8-pCPT-2'-O-Me-cAMP. (D) Quantitative analysis of active Rap1 immunoreactivity. Significantly higher hippocampal GTP-Rap1 levels were observed in the hemisphere that received 8-pCPT-2'-O-Me-cAMP infusions. Data are expressed as mean \pm SEM. ${ }^{*} P<0.05,{ }^{*} P<0.01$

infused with $0,0.5$, or $5 \mu$ g of 8-pCPT-2'-O-Me-cAMP (Axxora) and conditioned as described above. ANOVA revealed a significant effect of drug treatment on memory formation $\left(F_{(2,26)}=10.68, P=\right.$ $0.0004)$, again resulting in an inverted U-shaped dose-response curve (Fig. 1B). Post-hoc analysis showed that this difference was due to enhanced freezing in the low-dose group relative to both the vehicle and high-dose groups $(P s<0.01$, Student-NewmanKeuls). These data suggest that the activation of Epac is sufficient to enhance memory consolidation. However, further experiments were needed to test the behavioral and molecular specificity of the Epac agonist in vivo, and to minimize any confounding effects of PKA.

Since Epac has previously been reported to activate the neuroplasticity-related G protein Rap1 in vitro (de Rooij et al. 1998), we tested whether 8-pCPT-2'-O-Me-cAMP would also activate Rap1 in the hippocampus. Using a within-subject design, separate groups of mice were infused with 8-pCPT-2'-O-Me-cAMP $(0.5 \mu \mathrm{g})$ in one hippocampus and saline in the other. The hemisphere that received drug was counterbalanced. Hippocampi were then removed and assayed for Rap1 activity. Hippocampal extracts containing $1500 \mu \mathrm{g}$ of protein were then assayed with a Rap1 activation kit (Upstate). Briefly, lysates were incubated with glutathione-agarose beads precoupled with glutathioneS-transferase (GST) fusion protein, which contains a Rap1-binding domain from the human guanine nucleotide exchange factor specific for the Ras protein Ral. The GST fusion protein precipitates active Rap1 (GTP-Rap1) from the extracts. Samples were then analyzed by Western blotting using a Rap1 antibody (Upstate). As expected, agonist-infused hippocampi had significantly higher

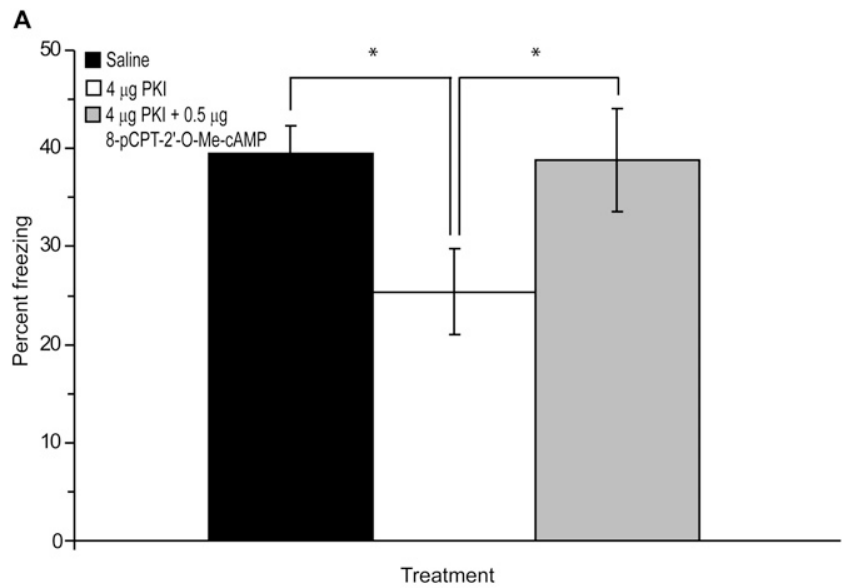

B

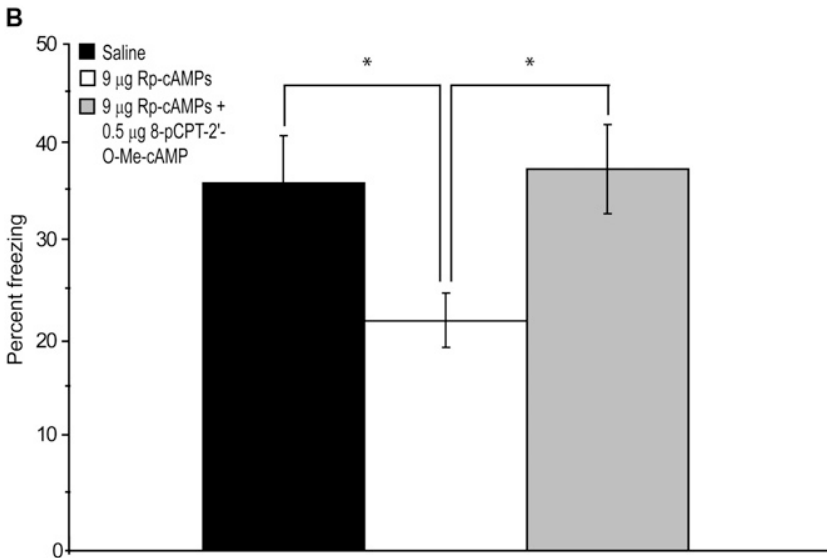

Treatment

Figure 2. Coinfusion of the Epac-specific activator with a PKA inhibitor leaves fear memory intact. (A) Inhibition of PKA with PKI significantly impaired contextual fear memory relative to saline-treated animals, whereas the combination of PKI and 8-pCPT-2'-O-Me-cAMP blocked this effect (saline, $n=10$; PKI, $4 \mu \mathrm{g}, n=10$; PKI [4 $\mu \mathrm{g}]+8$-pCPT-2'-O-MecAMP $[0.5 \mu \mathrm{g}], n=9)$. (B) The coinfusion of 8-pCPT-2'-O-Me-cAMP with Rp-CAMPS-enhanced long-term memory relative to Rp-cAMPS infusion alone (saline, $n=9$; Rp-cAMPS, $9 \mu \mathrm{g}, n=9$; Rp-cAMPS [9 $\mu \mathrm{g}]+8$-pCPT-2' O-Me-cAMP $[0.5 \mu \mathrm{g}], n=10$ ). Data are expressed as mean \pm SEM. ${ }^{*} P<$ 0.05 . 
levels of active Rap1 relative to saline-infused hippocampi $(P=$ 0.05 , paired $t$-test; Fig. $1 C$ ). Together with previous findings linking Rap1 to hippocampus-based memory formation (Morozov et al. 2003), these results indicate that Epac-mediated memory enhancements may act through an up-regulation in Rap1 signaling.

Due to the possibility that 8-pCPT-2'-O-Me-cAMP might also activate PKA, we examined the effect of the Epac agonist when coinfused with specific inhibitors of PKA. This approach has also been used to validate the action of this agonist in hippocampal long-term potentiation studies (Gelinas et al. 2008) and in various in vitro studies (Holz et al. 2008). First, we examined the effects of the Epac agonist when coinfused with the PKA inhibitor PKI(14-22)-amide (PKI, Assay Designs). This form of PKI is myristoylated on the $\mathrm{N}$ terminus to allow cell membrane permeability, and selectively inhibits the free catalytic subunit of PKA (Glass et al. 1989). In this experiment, a single $1.5-\mathrm{mA}$ footshock was used to induce high enough levels of freezing, such that PKArelated memory deficits would be detectable. Figure $2 \mathrm{~A}$ shows that the infusion of PKI $(4 \mu \mathrm{g})$ alone significantly impaired the consolidation of contextual fear memory. However, these deficits were overcome when 8-pCPT-2'-OMe-cAMP $(0.5 \mu \mathrm{g})$ was coinfused with PKI $(4 \mu \mathrm{g})$. ANOVA revealed an overall effect of treatment group on freezing $\left(F_{(2,26)}=4.71, P=0.02\right)$, where posthoc analysis demonstrated significant differences in freezing between the PKI group relative to both the vehicle and the Epac agonist + PKI groups $(P s<0.05$, Student-Newman-Keuls).

We also examined whether memory deficits induced by the well-characterized PKA inhibitor Rp-cAMPS (Dostmann 1995) could be rescued with the Epac agonist. As expected, mice receiving intrahippocampal infusions of Rp-cAMPS $(9 \mu \mathrm{g})$ after a $1.5-\mathrm{mA}$ footshock showed impaired contextual fear memory (Sananbenesi et al. 2002), but displayed normal memory when the Epac agonist $(0.5$ $\mu \mathrm{g})$ and PKA inhibitor were coinfused. ANOVA revealed an overall effect of treatment group on freezing $\left(F_{(2,25)}=4.04, P=\right.$ $0.03)$, where post-hoc analysis demonstrated significant differences in freezing between the Rp-cAMPS group relative to both the vehicle and the Epac agonist + Rp-cAMPS groups $(P s<0.05$, StudentNewman-Keuls). Thus, the data provide strong behavioral evidence that Epac can modulate memory independent of PKA and can rescue deficits caused by reduced PKA signaling.

Next, we determined the specificity of the Epac agonist on a molecular level. To do so, we took advantage of the fact that PKA is specifically required to phosphorylate the GluR1 subunit of AMPAtype glutamate receptors at Ser845 (Lee et al. 2000; Whitlock et al. 2006). Thus, pSer845 levels can be assayed to measure PKA activity and the specificity of the Epac agonist. A within-subjects design was used to measure pSer845 levels after

B

C

15 min post-infusion as mean \pm SEM. intrahippocampal infusion of either vehicle, Sp-cAMPS $(4.5 \mu \mathrm{g})$, 8-pCPT-2'-O-Me-cAMP $(0.5 \mu \mathrm{g})$, or 8-pCPT-2'-O-Me-cAMP $(0.5 \mu \mathrm{g})$ + PKI $(4 \mu \mathrm{g})$. Mice were sacrificed 15 or $45 \mathrm{~min}$ after drug infusion, after which the hippocampi were removed and assayed by Western blotting for phospho- and total GluR1 levels. These time points were chosen to evaluate whether the Epac agonist might activate PKA directly (i.e., with kinetics similar to cAMP) or indirectly, requiring a longer period of time to alter pSer845 levels. Figure 3A shows that mice sacrificed $15 \mathrm{~min}$ after Sp-cAMPS infusions had significantly greater pSer845 levels $(P=0.04$, paired $t$-test) in the drug-infused side relative to the saline-treated side. Similarly, Sp-cAMPS-treated mice sacrificed 45 min later showed a strong trend toward a significant increase in pSer845 levels $(P=$ 0.06 , paired $t$-test), possibly due to the long half-life of Sp-cAMPS. Interestingly, pSer845 levels appear to be increased in the vehicletreated hippocampi of mice that also received Sp-cAMPS relative to other vehicle groups. This could be due to the propagation of

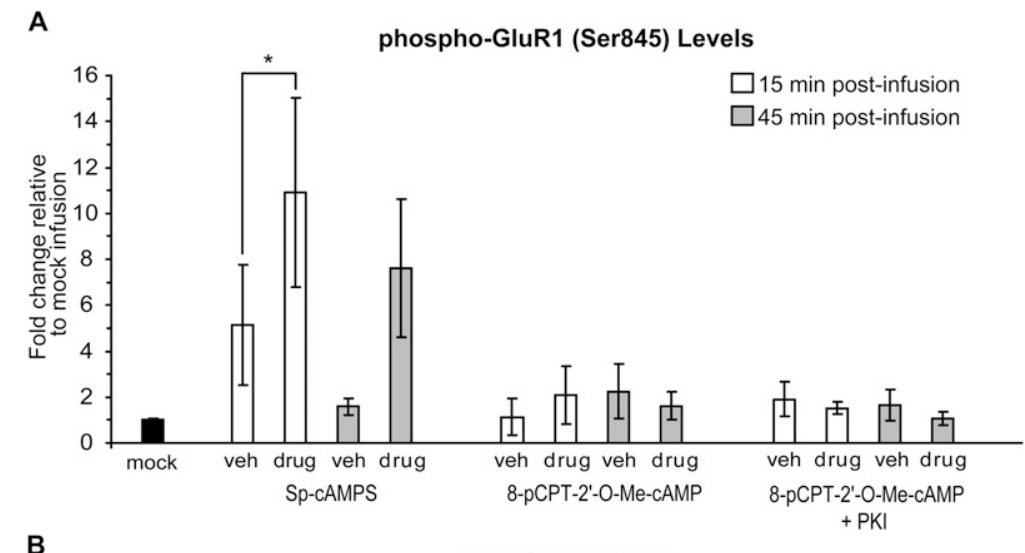

Total GluR1 Levels

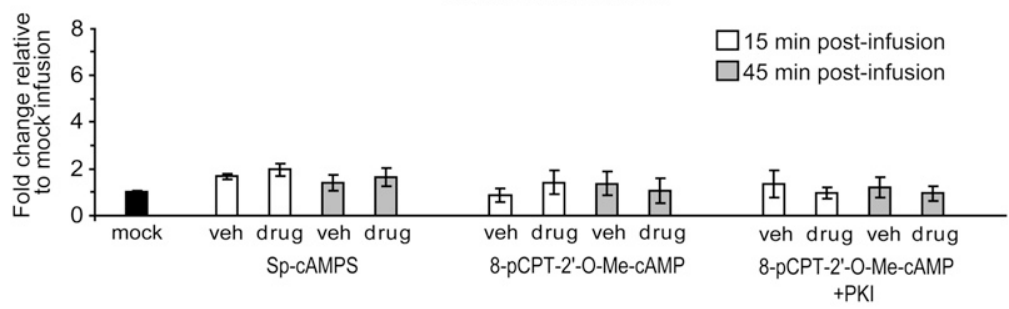

D

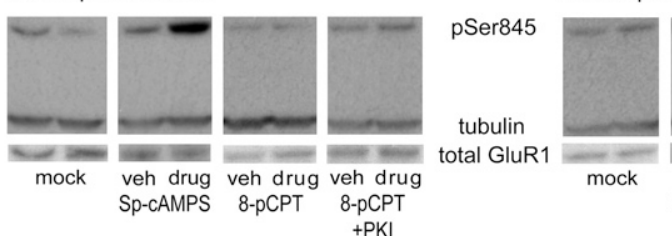

45 min post-infusion

Figure 3. Infusion of the Epac-specific agonist does not change PKA-dependent phosphorylation of GluR1 receptor subunits in the hippocampus. Phospho-GluR1 (pSer845) $(A)$ and total GluR1 (B) levels in the hippocampus 15 or 45 min post-drug infusion (open and shaded bars, respectively). (A) pSer845 levels were significantly increased $15 \mathrm{~min}$ after unilateral infusion of Sp-cAMPS $(4.5 \mu \mathrm{g})$ relative to the saline-treated side ( $\left.{ }^{*} P=0.04\right)$. Infusions of the Epac agonist or the combination of the agonist and PKI had no effect at either time point relative to their respective vehicle-treated hippocampi (8-pCPT-2'-OMe-cAMP, $0.5 \mu \mathrm{g}$; PKI $[4 \mu \mathrm{g}]+8$-pCPT-2'-O-Me-cAMP [0.5 $\mu \mathrm{g}])$. A strong trend $(P=0.06)$ toward an increase in pSer845 levels was observed for the Sp-cAMPS-infused hippocampi at $45 \mathrm{~min} . n=5$ for all treatment groups and time points. (B) Total GluR1 levels were unaffected by drug treatments at either time point. $(C, D)$ Representative immunoblots of pSer845 (1:2000, Millipore), $\beta$-tubulin $(1: 20000$, Sigma), and total GluR1 (1:2000, Millipore) levels $15 \mathrm{~min}(C)$ or $45 \mathrm{~min}(D)$ after infusion. All values were normalized to $\beta$-tubulin levels within individual samples to control for differences in total protein loaded, and then to mice that received mock injections (black bars in $A$ and $B, n=4$ ). Data are expressed 
activity induced in the drug-treated hemisphere to the contralateral side via commissural connectivity. Nevertheless, the Epac agonist alone had no effect on pSer845 levels, nor did the agonist in combination with PKI at either time point $\left(P_{\mathrm{S}}>0.05\right.$, paired $t$-tests). Finally, total GluR1 levels were not significantly altered in any of the treatment groups or time points $(P \mathrm{~s}>0.05$, paired $t$-tests; Fig. 3B). Thus, the memory enhancements observed after treatment with the Epac agonist and the ability of the agonist to rescue PKA-related memory deficits were not due to increases in PKA activity and suggest that Epac can, indeed, influence memory consolidation independent of PKA.

The purpose of the present study was to determine whether the cAMP-sensitive molecule Epac can influence memory formation previously thought to occur mainly through the activity of PKA. Our findings demonstrate that Epac is able to modulate memory consolidation, thereby broadening our understanding of cAMP signaling in memory formation. While there may be some interaction between the Epac and PKA signaling pathways (Nijholt et al. 2008), the nature of this interaction and its effect on memory consolidation remains to be determined. It is worth noting that cAMP-dependent PKA signaling does not have uniform effects on memory formation within all brain regions (Arnsten et al. 2005). Likewise, the effects of Epac activation in different regions will require further investigation. Importantly, these results provide the basis for the development of novel cognition-enhancing drugs that target specific components of the cAMP-Epac signaling pathway, rather than broad activators of cAMP (e.g., rolipram) (Bach et al. 1999). Indeed, such an approach might be warranted in that mutations in the Epac gene and altered levels of expression have been linked to autism (Bacchelli et al. 2003) and Alzheimer's disease (McPhee et al. 2005), respectively.

\section{Acknowledgments}

This work was supported by NMH P50-MH064045 (T.A.). (R. Gur, PI). P.J.H. was supported by a NIH T32NS00743-11 grant in developmental disabilities (M. Robinson, PI) and by a NSF Minority Postdoctoral Fellowship 0706858. We thank Dr. Steven Thomas for his suggestions in experiment design and Christopher G. Vecsey for comments on the manuscript.

\section{References}

Abel T, Nguyen PV. 2008. Chapter 6 regulation of hippocampus-dependent memory by cyclic AMP-dependent protein kinase. Prog Brain Res 169: $97-115$.

Arnsten AF, Ramos BP, Birnbaum SG, Taylor JR. 2005. Protein kinase A as a therapeutic target for memory disorders: Rationale and challenges. Trends Mol Med 11: 121-128.

Bacchelli E, Blasi F, Biondolillo M, Lamb JA, Bonora E, Barnby G, Parr J, Beyer KS, Klauck SM, Poustka A, et al. 2003. Screening of nine candidate genes for autism on chromosome $2 \mathrm{q}$ reveals rare nonsynonymous variants in the cAMP-GEFI gene. Mol Psychiatry 8: 916-924.

Bach ME, Barad M, Son H, Zhuo M, Lu YF, Shih R, Mansuy I, Hawkins RD, Kandel ER. 1999. Age-related defects in spatial memory are correlated with defects in the late phase of hippocampal long-term potentiation in vitro and are attenuated by drugs that enhance the cAMP signaling pathway. Proc Natl Acad Sci 96: 5280-5285.

Bos JL. 2006. Epac proteins: Multi-purpose cAMP targets. Trends Biochem Sci 31: $680-686$.

Calabrese EJ, Baldwin LA. 2001. Hormesis: U-shaped dose responses and their centrality in toxicology. Trends Pharmacol Sci 22: 285-291.

Christensen AE, Selheim F, de Rooij J, Dremier S, Schwede F, Dao KK, Martinez A, Maenhaut C, Bos JL, Genieser HG, et al. 2003. cAMP analog mapping of Epac1 and cAMP kinase. Discriminating analogs demonstrate that Epac and cAMP kinase act synergistically to promote PC-12 cell neurite extension. J Biol Chem 278: $35394-$ 35402.

de Rooij J, Zwartkruis FJ, Verheijen MH, Cool RH, Nijman SM, Wittinghofer A, Bos JL. 1998. Epac is a Rap1 guanine-nucleotide-exchange factor directly activated by cyclic AMP. Nature 396: $474-477$.

Dostmann WR. 1995. $\left(R_{\mathrm{P}}\right)$-cAMPS inhibits the cAMP-dependent protein kinase by blocking the cAMP-induced conformational transition. FEBS Lett 375: 231-234.

Enserink JM, Christensen AE, de Rooij J, van Triest M, Schwede F, Genieser HG, Doskeland SO, Blank JL, Bos JL. 2002. A novel Epac-specific cAMP analogue demonstrates independent regulation of Rap1 and ERK. Nat Cell Biol 4: 901-906.

Gelinas JN, Banko JL, Peters MM, Klann E, Weeber EJ, Nguyen PV. 2008. Activation of exchange protein activated by cyclic-AMP enhances longlasting synaptic potentiation in the hippocampus. Learn Mem 15: 403411

Glass DB, Lundquist LJ, Katz BM, Walsh DA. 1989. Protein kinase inhibitor(6-22)-amide peptide analogs with standard and nonstandard amino acid substitutions for phenylalanine 10. Inhibition of cAMP-dependent protein kinase. J Biol Chem 24: 14579-14584.

Holz GG, Chepurny OG, Schwede F. 2008. Epac-selective cAMP analogs: New tools with which to evaluate the signal transduction properties of cAMP-regulated guanine nucleotide exchange factors. Cell Signal 20: $10-20$.

Kawasaki H, Springett GM, Mochizuki N, Toki S, Nakaya M, Matsuda M, Housman DE, Graybiel AM. 1998. A family of cAMP-binding proteins that directly activate Rap1. Science 282: 2275-2279.

Kelly MP, Stein JM, Vecsey CG, Favilla C, Yang X, Bizily SF, Esposito MF Wand G, Kanes SJ, Abel T. 2009. Developmental etiology for neuroanatomical and cognitive deficits in mice overexpressing Galphas, a G-protein subunit genetically linked to schizophrenia. Mol Psychiatry 14: 398-415.

Lee HK, Barbarosie M, Kameyama K, Bear MF, Huganir RL. 2000. Regulation of distinct AMPA receptor phosphorylation sites during bidirectional synaptic plasticity. Nature 405: 955-959.

McPhee I, Gibson LC, Kewney J, Darroch C, Stevens PA, Spinks D, Cooreman A, MacKenzie SJ. 2005. Cyclic nucleotide signalling: A molecular approach to drug discovery for Alzheimer's disease. Biochem Soc Trans 33: 1330-1332.

Morozov A, Muzzio IA, Bourtchouladze R, Van-Strien N, Lapidus K, Yin D, Winder DG, Adams JP, Sweatt JD, Kandel ER. 2003. Rap1 couples cAMP signaling to a distinct pool of p42/44MAPK regulating excitability, synaptic plasticity, learning, and memory. Neuron 39: 309325.

Nijholt IM, Dolga AM, Ostroveanu A, Luiten PG, Schmidt M, Eisel UL. 2008. Neuronal AKAP150 coordinates PKA and Epac-mediated PKB/Akt phosphorylation. Cell Signal 20: 1715-1724.

Ouyang M, Zhang L, Zhu JJ, Schwede F, Thomas SA. 2008. Epac signaling is required for hippocampus-dependent memory retrieval. Proc Natl Acad Sci 105: 11993-11997.

Sananbenesi F, Fischer A, Schrick C, Spiess J, Radulovic J. 2002. Phosphorylation of hippocampal Erk-1/2, Elk-1, and p90-Rsk-1 during contextual fear conditioning: Interactions between Erk-1/2 and Elk-1. Mol Cell Neurosci 21: 463-476.

Souza MM, Mello e Souza T, Vinade ER, Rodrigues C, Choi HK, Dedavid e Silva TL, Medina JH, Izquierdo I. 2002. Effects of posttraining treatments in the posterior cingulate cortex on short- and long-term memory for inhibitory avoidance in rats. Neurobiol Learn Mem 77: 202210

Ster J, De Bock F, Guerineau NC, Janossy A, Barrere-Lemaire S, Bos JL, Bockaert J, Fagni L. 2007. Exchange protein activated by cAMP (Epac) mediates cAMP activation of p38 MAPK and modulation of $\mathrm{Ca}^{2+}$ dependent $\mathrm{K}^{+}$channels in cerebellar neurons. Proc Natl Acad Sci 104: 2519-2524.

Tronson NC, Wiseman SL, Olausson P, Taylor JR. 2006. Bidirectional behavioral plasticity of memory reconsolidation depends on amygdalar protein kinase A. Nat Neurosci 9: 167-169.

Whitlock JR, Heynen AJ, Shuler MG, Bear MF. 2006. Learning induces long-term potentiation in the hippocampus. Science 313: 10931097.

Yusta B, Ortiz-Caro J, Pascual A, Aranda A. 1988. Comparison of the effects of forskolin and dibutyryl cyclic AMP in neuroblastoma cells: Evidence that some of the actions of dibutyryl cyclic AMP are mediated by butyrate. J Neurochem 51: 1808-1818.

Received September 19, 2008; accepted in revised form March 31, 2009. 


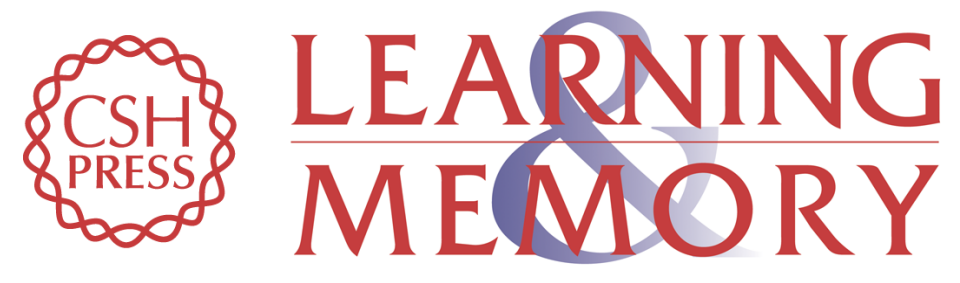

\section{Exchange protein activated by cAMP enhances long-term memory formation independent of protein kinase $A$}

Nan Ma, Ted Abel and Pepe J. Hernandez

Learn. Mem. 2009, 16:

Access the most recent version at doi:10.1101//m.1231009

References This article cites 26 articles, 7 of which can be accessed free at:

http://learnmem.cshlp.org/content/16/6/367.full.html\#ref-list-1

License

Email Alerting Receive free email alerts when new articles cite this article - sign up in the box at the Service top right corner of the article or click here. 